\title{
Long term follow up of spinal cord injury caused by penetrating missiles
}

\author{
M E Brooks MD, R Brouner MD, A Ohry MD
}

Department of Neurologic Rehabilitation, Chaim Sheba Medical Center, Tel Hashomer, Israel 52621 (affiliated with the Sackler School of Medicine, Tel Aviv University, Tel Aviv, Israel).

Eighty-four spinal cord injured patients (SCIP) injured as a result of penetrating missiles were categorised according to: neurological level of injury, age at time of injury, circumstances of injury, missile type, initial treatment, duration of injury, and ethnic background. Evaluations and comparisions were made concerning: life habits, family status, education, employment, and mental well being. A discussion of complicating factors, both physical and psychological, and their relation to the final rehabilitation result is presented.

Key words: spinal cord injury; bullet wounds; trauma; long term study; psychosocial factors

\section{Introduction and methods}

One hundred and four spinal cord injured patients (SCIP) injured as a result of penetrating missiles were categorised according to: neurological level of injury, age at time of injury, circumstances of injury, missile type, initial treatment, duration of injury, and ethnic background. Evaluations and comparisons were made concerning: life habits, family status, education, employment, and mental well being. Information for this study came from the comprehensive annual follow up of wounded veterans in our clinics. Inclusion criteria in this study were bullet or shrapnel wounds causing neurological damage of clinical significance in those patients who received their follow up care in our institution and were at least 2 years post trauma. These criteria eliminated 20 SCIP. Of the remaining 84 patients, 80 men and 4 women from 21 to 68 years old, 47 were less than 22 years old (age range of 17-52 years) at the time of injury. Thirtythree of the SCIP were injured in battle, and the remaining 51 patients were paralysed as a result of suicide attempts, murder attempts, accidents, or terrorist attacks. Fiftythree wounds were from bullets, 28 were from shrapnel and in 3 cases the cause was unknown. Fifty-two SCIP were complete lesions and 32 were incomplete lesions, the injury level being: 16 cervical, 23 above T6, 26 below T6 in the thoracic cord, and 19 in the lumbar area. Thirty-nine patients were initially treated surgically, 42 SCIP were treated conservatively, and in 3 cases the initial treatment was unknown. The ethnic distribution included: 51 SCIP of European origin, 31 SCIP of Afro-Asian origin and 2 Arab patients. Twenty-eight SCIP were injured more than 20 years ago, 41 SCIP were injured between 10 and 20 years ago, and 15 SCIP are less than 10 years post trauma. Statistical analysis included the chi-square test for matched pairs and the single tailed t-test.

\section{Results}

Table I shows the most frequent late medical complications in relation to completeness and to the level of the lesion. Complications noted with higher cord lesions, especially cervical, included: (1) an increase in tendon contractures $(p<0.05)$, (2) increase in readmission to the hospital $(p<0.025)$, (3) obesity, and (4) hypertension. Pain was a problem in $55 \%$ of all SCIP. Social and family factors were affected neither by the completeness of the lesion nor by level of cord injury. However, the SCIP with the incomplete cord lesion felt a greater lack of acceptance by his peer group $(p<0.05)$. Lower level SCIP had more frequent and more complete sexual intercourse $(p<0.001)$. The SCIP with 
Table I Distribution of late-onset medical complications

\begin{tabular}{|c|c|c|c|c|c|c|c|c|}
\hline Complication & SCIP & $\%$ & Complete & Incomplete & $\mathrm{C} 5-\mathrm{C} 8$ & D1-D6 & D7-D12 & L1-15 \\
\hline Pain & 50 & 56 & 27 & 23 & 6 & 11 & 16 & 16 \\
\hline \multirow{2}{*}{\multicolumn{9}{|c|}{$\begin{array}{l}\text { Recurrent urinary } \\
\text { tract infection }\end{array}$}} \\
\hline & 45 & 50 & 32 & 10 & 9 & 13 & 14 & 6 \\
\hline Erysipelas & 25 & 30 & 19 & 6 & 4 & 6 & 9 & 6 \\
\hline Obesity & 25 & 30 & 14 & 11 & 2 & 9 & 9 & 5 \\
\hline Pressure sores & 24 & 29 & 18 & 6 & 5 & 8 & 7 & 4 \\
\hline Haemorrhoids & 19 & 23 & 13 & 6 & 5 & 4 & 6 & 4 \\
\hline Contractures & 17 & 20 & 11 & 6 & 10 & 5 & 2 & 0 \\
\hline \multicolumn{9}{|l|}{ Frequent } \\
\hline readmissions & 15 & 18 & 11 & 4 & 6 & 2 & 4 & 3 \\
\hline Hypertension & 14 & 17 & 9 & 5 & 1 & 2 & 7 & 4 \\
\hline \multicolumn{6}{|l|}{ Autonomic } & 4 & 1 & 0 \\
\hline $\begin{array}{l}\text { Respiratory } \\
\text { problems }\end{array}$ & 5 & 6 & 4 & 1 & 5 & 2 & 2 & 1 \\
\hline
\end{tabular}

incomplete lesions reported more complete sexual relations $(p<0.0001)$, and fathered more children after the trauma than the SCIP with a complete lesion. ${ }^{1,2}$

No differences concerning medical or social complications were noted with reference to age at the time of trauma, type of projectile, or initial treatment. Concerning ethnic origin, SCIP of European origin had a greater tendency to have haemorrhoids $(p<0.05)$, and had twice the incidence of erysipelas. After injury, more SCIP of European origin continued with formal education $(p<0.025)$ and worked in gainful employment $(p<0.05)$ than the non European.

With the aging of the injured patients, there is an increase in the occurrence of medical complications; thus $18 \%$ of those SCIP's who worked required hospitalisation. Table II shows the specific medical complications related to age. The problem of pressure sores is a continuing one with an incidence of up to $40 \% 30$ years after injury. Plastic surgical procedures for pressure sores was necessary for $26 \%$ of all SCIP. Haemorrhoids appeared in the second decade after injury. Twenty-five of the patients with haemorrhoids required ligation, or injection. Urological surgical procedures were required in more than $60 \%$ of all the SCIP who were 30 years post trauma, and $40 \%$ of all SCIP patients underwent some urological procedure. Thirty per cent of all SCIP were overweight. Nineteen per cent had a decrease in work ability as documented by hand ergometry. Less than $33 \%$ of the SCIP patients could walk even with aids (crutches and braces). The number of married patients increases with time from $40 \%$ in the first decade after injury to $85 \%$ after 30 years. Fifty per cent of all the SCIP reported no sexual intercourse and $25 \%$ reported complete sexual relations, with a gradual decrease by the third decade after injury. Eighty per cent of all the married SCIP became parents or adopted children after their injury. Most of the $50 \%$ of the SCIP who continued with higher education, did so during the first years immediately after injury. Thirty-three per cent of the SCIP obtained university degrees. After 20 years $90 \%$ of all the SCIP worked at gainful employment while $80 \%$ had full time jobs; $18 \%$ were unsatisfied with their jobs. Twenty-one per cent of the patients injured more than 20 years ago received psychiatric treatment; whereas $40 \%$ of the SCIP injured less than 20 years ago have received psychiatric help. As time passes, the SCIP tends to accept the effects of the SCI, and only $7 \%$ did not do so 20 years after trauma. Despite this, one third of the SCIP showed clinical signs of depression (Table II). Chronic diseases such as hypertension, diabetes mellitus, and ischaemic cardiac dis- 
Table II Medical and psychosocial factors as a function of aging

\begin{tabular}{|c|c|c|c|}
\hline \multirow[t]{2}{*}{ Factor } & \multicolumn{3}{|c|}{$\begin{array}{l}\text { Years injured } \\
\text { (Total patients) }\end{array}$} \\
\hline & $\begin{array}{l}<10 \\
(15)\end{array}$ & $\begin{array}{c}10-20 \\
(41)\end{array}$ & $\begin{array}{l}>20 \\
(28)\end{array}$ \\
\hline Haemorrhoids & 0 & 9 & 10 \\
\hline Urological surgery & 3 & 13 & 18 \\
\hline $\begin{array}{l}\text { Recurrent pressure } \\
\text { sores }\end{array}$ & 2 & 11 & 11 \\
\hline $\begin{array}{l}\text { Recurrent urinary } \\
\text { tract infection }\end{array}$ & 6 & 21 & 15 \\
\hline Obesity & 4 & 8 & 13 \\
\hline Married after injury & $4 / 10$ & $23 / 31$ & $17 / 20$ \\
\hline $\begin{array}{l}\text { Reported sexual } \\
\text { relations }\end{array}$ & 4 & 15 & 4 \\
\hline $\begin{array}{l}\text { Reported no sexual } \\
\text { relations }\end{array}$ & 7 & 17 & 15 \\
\hline $\begin{array}{l}\text { Raised children after } \\
\text { injury }\end{array}$ & - & $19 / 33$ & $20 / 25$ \\
\hline Smokers & 4 & 16 & 8 \\
\hline Higher education & 7 & 22 & 11 \\
\hline Work & 1 & 30 & 25 \\
\hline $\begin{array}{l}\text { Decreased work } \\
\text { ability }\end{array}$ & 2 & 5 & 9 \\
\hline $\begin{array}{l}\text { Received psychiatric } \\
\text { or psychological } \\
\text { support }\end{array}$ & 6 & 16 & 6 \\
\hline Depressed & 6 & 10 & 9 \\
\hline $\begin{array}{l}\text { Non acceptance of } \\
\text { disability }\end{array}$ & 5 & 10 & 2 \\
\hline $\begin{array}{l}\text { Non acceptance by } \\
\text { peers }\end{array}$ & 4 & 14 & 8 \\
\hline
\end{tabular}

ease are twice as common in the older aged SCIP compared to the normal population. ${ }^{3}$

\section{Discussion}

Israel is a small country (4.5 million citizens). The population is heterogenous from many national and ethnic backgrounds. The rehabilitation services of the Ministry of Defence for the military SCIP are concentrated in one centre for initial hospitalisation, and for yearly follow up. Thus while the cohort of this study is relatively small, the care is uniform and the goal is to return patients to a productive satisfying role in society and with minimal future complications. ${ }^{4}$

From the above data several generalisations are evident: the higher the lesion, the more frequent are post traumatic complications, thus reducing the possible benefits of rehabilitation; the older the patient at the time of injury, the less successful is the final rehabilitation outcome. ${ }^{5}$ The younger soldier injured in battle during the duration of obligatory military service is more motivated and is rehabilitated with better results than is the civilian or the reserve duty soldier injured under the same circumstances. High velocity missiles produce injuries with more complicated rehabilitation problems than do those produced by shrapnel. The initial treatment, conservative versus surgical, of the spinal column has no direct effect on the subsequent rehabilitation programme. ${ }^{6-8}$

The late appearance of common medical complications in the SCIP, and the number of urological and plastic surgical treatments after the initial hospitalisation probably reflect the fact that all high level SCIP who are supported by the Ministry of Defence have constant 24 hour attendants. ${ }^{9,10}$ The increased number of SCIP who have haemorrhoids probably reflects the inappropriate seating on cushions and wheelchairs some years ago, and the prolonged period of sitting for defecation. Erysipelas probably results from wearing inappropriate footware (sandals without socks), inappropriate foot care, and the improper cutting of toenails. The high standard of education and of employment is due to the benefits that the Ministry of Defence extends to wounded veterans.

\section{References}

1 Francois N, Maury M, (1987) Sexual aspects in paraplegic patients. Paraplegia 25: 289-292.

2 Comarr AE (1977) Sexual function in patients with spinal cord injury. In: Pierce DS, Nickel VH, eds. The Total Care of Spinal Cord Injuries. Boston: 171-180.

3 Yekutiel M, Brooks ME, Ohry A, Yarom J, Carel R (1989) The prevalence of hypertension, ischemic heart disease and diabetes in traumatic spinal cord injured patients and amputees. Paraplegia, 27: 58-62.

4 Kraus JF, Franti CE, Borhan NO, Riggins RS, (1979) Survival with an acute spinal cord injury. J Chron 


\section{Brooks et al}

Dis 32: 269-283.

5 Yarkony GM, Roth EJ, Heinemann AW, Lovell LL, (1988) Spinal cord injury outcome: the impact of age. J Clin Epid 41: 173-177.

6 Benzel EC, Hadlen TA, Coleman GE (1987) Civilian gunshot wounds to the spinal cord and cauda equin. $J$ Neurosurg 20: 281-284.

7 Six E, Alexander E, Kelly DE Jr, Davis CH Jr, McWhorter JM, (1979) Gunshot wounds to the spinal cord. $S$ Med J, 72: 699-702.

8 Yashon D, Jane JA, White RG (1970) Prognosis and management of spinal cord and cauda equina bullet injuries in 65 civillians. $J$ Neurosurg 32: 163-170.

9 Jacobs GB, Berg RA (1971) Treatment of spinal cord injuries in a war zone. J Neurosurg 34: 164-167.

10 Jacobson SA, Bors E (1973) Spinal cord injuries in Vietnamese combat. Paraplegia 7: 263-281. 